\title{
Meta-Analysis of Semi-Occluded Vocal Track Exercise Studies on Acoustic, Aerodynamic, and Electroglottographic Results
}

\author{
Jaeock Kim \\ Division of Speech Pathology Education, Graduate School of Education, Kangnam University, Yongin, Korea
}

Correspondence: Jaeock Kim, $\mathrm{PhD}$

Division of Speech Pathology Education, Graduate School of Education, Kangnam University,

40 Gangnam-ro, Giheung-gu, Yongin 16979, Korea

Tel: $+82-31-280-3221$

Fax: +82-31-280-3479

E-mail: jaeock@gmail.com

Received: April 19, 2019

Revised: May 15, 2019

Accepted: May 27, 2019

This research was supported by 2016 Kangnam University Research Grants.
Objectives: Recently semi-occluded vocal tract exercise (SOVTE) is commonly used in voice clinic and research. This study aimed at investigating the effects of SOVTE on acoustic, aerodynamic, and electroglottographic analysis in patients with dysphonia using metaanalysis. It also examined whether there was differences in the effects by type of voice disorders. Methods: Eighteen studies published between 2000 and 2018 which met the inclusion and exclusion criteria were selected from 9 database. These 18 studies were divided into 37 subjects by SOVTE subtype and dysphonic type. The effect sizes and mean effect sizes of acoustic (fundamental frequency [F0], sound pressure level [SPL], \%jitter, \%shimmer, noise-to-harmonic ratio [NHR]), aerodynamic (subglottal pressure [Psub], phonation threshold pressure [PTP], glottal airflow, glottal resistance), and electroglottographic (closed quotient [CQ]) analysis were calculated by Hedges' $g$ using standardized mean difference. Results: Based on the results of meta-analysis, SOVTE significantly changed acoustic measures, but did not change aerodynamic measures and CQ. However, when the subitems of those measures were examined, \%jitter, \%shimmer, NHR, Psub, PTP, glottal resistance were significantly changed by SOVTE. In addition, the acoustic analysis, \%jitter, aerodynamic analysis, Psub, and CQ showed significant differences among the different types of voice disorders. Conclusion: The study shows that SOVTE reduced voice problems measured in acoustic, aerodynamic, and electroglottographic analysis and can be applied for hyperfunctional voice disorders and glottal gap.

Keywords: Meta-analysis, Semi-occluded vocal tract exercise, Acoustic, Aerodynamic, Electroglottographic
전 일생에 걸쳐 성인이 경험하는 음성장애 유병률(lifetime prevalence)은 약 $30 \%$ 이며, 일정 시점에서 성인이 자가 보고하는 음성 장애 유병률(point prevalence)은 약 6.6\%-7.5\%에 달한다(Cohen, 2010; as cited Kaspner-Smith, Hunter, Kirkham, Cox, \& Titze, 2015). 음성장애의 중재를 위해 약물치료, 수술치료, 음성치료 등이 사용되는데, 이 중에서 음성치료는 다른 치료와 병행하여 사용되 기도 하고 단독으로 사용되기도 한다. 특히 기능적 음성장애의 경 우 행동치료를 기반으로 하는 음성치료가 효과적이다. 여러 음성치 료 중에서도 반폐쇄성도훈련(semi-occluded vocal tract exercise, SOVTE)은 성도의 과도한 긴장을 감소시키고 음질을 개선시키기
위한 치료기법으로 최근 임상에서 널리 사용되면서 그 효과가 입 증되고 있다.

SOVTE는 구강 전반부나 입술 부위와 같은 성도의 끝부분을 부 분적으로 폐쇄하고 그 단면적을 줄여서 발성하는 것으로, 구강 내 압력을 높여 성대에 가해지는 역압(back pressure, $\left.\mathrm{P}_{\mathrm{back}}\right)$ 을 상승시 키고 후두의 위치는 낮추며 인두는 넓힘으로써 성도의 음향학적 임피던스(impedance)를 증가시킨다. 증가된 임피던스는 성대에 가 해지는 부하(loading)를 감소시켜 성대의 진동을 효율적으로 보조 함으로써 발성 역치(phonation threshold)를 낮추고, 부분적으로 닫힌 성도에 의해 상승된 구강 내 압력은 성대의 윗면을 살짝 벌어 
지게 하여 성대가 과도하게 충돌하지 않으면서 진동하게 하고 배음 들의 진폭을 증가시킴으로써 발성 시 경제성과 효율성이 향상된다 (Andrade et al., 2016; Dargin, DeLaunary, \& Searl, 2016; Paes, Zambon, Yamasaki, Simberg, \& Behalu, 2013; Titze, 2001, 2006, 2018; Titze \& Laukkanen, 2007; Titze \& Story, 1997).

SOVTE는 입술떨기(lip trills), 혀떨기(tongue trills), 유성양순마 찰음[v:, z:, $\beta:$, 허밍(humming), 손으로 입 가리고 발성(hand-over mouth), 빨대발성(straw or tube phonation) 등의 다양한 기법들이 있다(Gaskill \& Erickson, 2008; Laukkanen, Titze, Hoffman, \& Finnegan, 2008; Lee, Lee, Lim, \& Choi, 2017; Simberg \& Laine, 2007; Titze, 2006; Vlot et al., 2017). 이 중에서 입술떨기, 혀떨기, 유 성양순마찰음, 물속에 빨대 끝을 넣는 빨대발성(water resistance therapy, WRT) 등은 성대 진동과 함께 다른 부위가 동시에 진동하 는 이중 진동원을 갖는다. 반면에 허밍, 손으로 입 가리고 발성, 빨 대 끝을 공기 중에 노출하는 빨대 발성(tube phonation with the distal end in air, TPA) 등은 성대 진동만이 유일한 진동원으로 작 용하는 단일 진동원을 갖는다(Kim, Lee, Choi, \& Choi, 2017; Lim, Choi, Kim, \& Choi, 2016; Titze, 2006).

다양한 SOVTE 기법들의 음성장애 중재효과에 관하여 국외를 중심으로 많은 연구들이 수행되고 있다. 음성의 문제가 없는 일반 인, 음성장애 환자, 가수, 동물이나 생체(in vivo) 등의 다양한 대상 에게 SOVTE를 실시한 후 대상자에 의한 자가 평가, 청지각적 평가, 음향학적 평가, 공기역학적 평가, 전기성문파형, stroboscopy 등을 이용한 후두내시경, 컴퓨터단층촬영(computerized tomography, $\mathrm{CT}$ ), 자기공명영상(magnetic resonance imaging, MRI) 등의 다양 한 검사를 통해 중재효과를 입증하고자 하였다(Andrade et al., 2016; Bele, 2005; Dargin et al., 2016; Denizoglu, Sahin, Bayra, \& Uygun, 2018; Enflo, Sundberg, Romedahl, \& McAllister, 2013; Hampala, Laukkanen, Guzman, Horáček, \& Švec, 2015; Mills, Hays, Al-Ramahi, \& Jiang, 2017; Titze, 2006; Yamasaki et al., 2017).

선행연구들에 따르면 SOVTE 기법이나 대상자 유형에 따라 서 로 상반되는 치료 결과들이 도출되기도 한다. SOVTE가 성도와 성 대에 미치는 공기역학적 변화로 성대 주변의 저항이나 성대 접촉 양상이 변화하는데, 그 양상들이 연구들마다 조금씩 다르게 보고 되고 있다(Andrade et al., 2016; Guzman et al., 2016; Lim et al., 2016). 가령, 입술떨기나 혀떨기를 시행한 후에 상부 성도의 증가된 압력 으로 인해 성문상압과 성문하압의 기압차인 통성문압(transglottal pressure)이 감소하고 발성역치압력(phonation threshold pressure, $\mathrm{PTP}$ )도 감소하면서 성대 진동의 진폭과 성대접촉률이 감소한다는 연구들이 있는 반면(Gaskill \& Erickson, 2008; Story, Laukkanen,
\& Titze, 2000), 다른 연구에서는 입술떨기나 혀떨기 훈련 후에 폐 로부터의 기류 증가와 성문하압의 상승으로 성대 진동 시 성대 가 장자리의 진폭과 성대접촉률이 증가하였다(Cordeiro, Montagnoli, Nemr, Menezes, \& Tsuji, 2012; Nam et al., 2018). 빨대발성을 이 용한 SOVTE를 적용한 경우에도 성대접촉률이 증가한 경우가 있 는 반면(Gaskill \& Quinney, 2012), 감소한 경우도 있었다(Guzman, Rubin, Muñoz, \& Jackson-Menaldi, 2013). 이렇게 동일한 기법의 SOVTE를 적용하였어도 연구마다 SOVTE가 성대에 미치는 역학 이나 중재효과의 차이가 발생할 수 있는데, 이러한 차이는 음성장 애 유형이나 중증도의 차이에서 기인하였을 수 있다. 즉 음성장애 를 중재할 때 음성장애의 유형이나 중증도를 정확하게 파악하고, 이에 적합한 음성치료 중재기법을 사용해야 한다. 이를 위해서는 음성치료의 효과를 보다 정확하고 체계적으로 파악할 필요가 있다.

최근 Mendes 등(2018)은 가수를 대상으로 빨대발성을 사용한 SOVTE의 중재효과에 관한 체계적 문헌고찰을 위해 Cochrane, LILACS, PubMed, SciELO의 4개의 데이터베이스에서 검색을 통 해 2012년부터 2017년까지 미국, 칠레, 스웨덴, 브라질에서 출간된 6편의 연구들을 분석하였다. 이 체계적 문헌고찰에 따르면, SOVTE 의 중재효과는 주로 자가보고식 음성평가, 구강내 압력, 발성역치 압력, 청지각적 평가, 음향학적 평가 및 전기성문파형 검사를 통해 분석되었고, 이 중에서 성문접촉률이 가장 많이 측정되었다. 그리 고 대부분의 연구에서 빨대발성은 음질, 성대 기능 및 성도 상태 등 에 긍정적인 영향을 초래하였다. 그러나 이 연구에서 분석된 연구 들은 대상자가 가수에만 국한되어 있고, 음성문제 여부에 대해서 는 고려하지 않았기 때문에 SOVTE가 음성장애에 미치는 중재효 과에 대해서는 파악하기 어렵다. 또한 빨대발성의 중재효과에만 한 정되어 있기 때문에 빨대발성 외의 다른 SOVTE 기법에 관한 종합 적인 중재효과를 살펴보기 어렵다.

이에 본 연구에서는 SOVTE가 음성장애 대상자에게 어떠한 영 향을 미치는지를 보다 객관적으로 분석하고자 음향학적, 공기역학 적 및 전기성문파형 검사와 같은 객관적 음성 평가들을 살펴본 선 행연구들을 체계적으로 고찰하고, SOVTE 중재효과의 종합적인 효과크기를 분석하고자 메타분석을 실시하였다. 또한음성장애 유 형에 따라SOVTE의 중재효과의 차이가 있는지를 살펴보았다.

본 연구의 연구문제는 다음과 같다.

1) SOVTE가 음성장애 대상자의 음향학적 검사에 미치는 효과 는 어떠한가?

2) SOVTE가 음성장애 대상자의 공기역학적 검사에 미치는 효 과는 어떠한가?

3) SOVTE가 음성장애 대상자의 전기성문파형 검사에 미치는 
효과는 어떠한가?

4) SOVTE가 음성장애 유형에 따라 음향학적, 공기역학적 및 전 기성문파형 검사에 미치는 효과의 차이가 있는가?

\section{연구방법}

\section{문헌 검색}

음성장애 대상자에게 SOVTE를 실시한 중재효과를 음향학적, 공기역학적 및 전기성문파형 검사로 분석한 연구들을 파악하고자 국내 1개(RISS) 및 국외 8개(Cochrane, EBSCO, EMBASE, ERIC, ProQuest, PsycINFO, PubMed, Science Direct)의 데이터베이스를 검색하였다. 검색에 포함된 연구들은 2000년부터 2018년 사이에 국내외 학술지에 게재된 연구들로 출판연도는 2018년 12월 31일자 까지로 제한하였다. 검색어는 'SOVTE 관련 용어(Lax Vox, LaxVox, semioccluded vocal tract, semi-occluded vocal tract, water resistance, flow resistance, tube, straw)' AND '발성이나 음성산출 용어(voice OR phonation)'로 하였다.

\section{문헌 선정}

문헌 검색에 의해 각 데이터베이스에서 검색된 연구의 편수는 총 1,094 편으로, RISS가 33편, Cochrane이 52편, EBSCO가 162편, EMBASE가 226편, ERIC이 21편, ProQuest가 196편, PsycINFO가 60 편, PubMed가 167편, Science Direct가 177편이었고, 이 중에서 중복인 연구 964 편을 제외한 130 편 중 동료 심사(peer review)가 이
루어지지 않고 전문(full-text) 이용이 어려운 13편과 영어나 한국 어 이외의 언어로 기술된 연구 2 편을 제외한 115 편의 연구를 살펴 보았다. 이 중에서 연구설계가 집단 간 사전-사후 비교연구 또는 집 단 내 사전-사후 비교연구인 경우 Borenstein, Hedges, Higgins와 Rothstein (2009, Chapter 40)에 따라 하나의 메타분석 연구에 서 로 다른 연구설계를 포함하여 효과크기를 계산할 수 있으므로 본 연구에 다른 두 가지 연구설계를 분석대상으로 포함하고, 단일대 상연구, 리뷰연구 또는 집단비교연구인 35 편은 제외하였다. 또한 연 구대상으로 음성문제가 있는 성인만을 포함하여 음성이 정상인 경 우나 아동, 동물 또는 생체를 대상으로 한 38편의 연구는 제외하였 다. 중재방법으로는 SOVTE 중에서 빨대 끝을 공기 중에 노출하는 경우(TPA)와 물속에 넣는 경우(WRT), 고음으로 불기, 입술떨기, 혀떨기 및 raspberry (입술떨기와 혀떨기를 동시에 실시)가 포함되 었고, 그 외 중재방법을 사용한 6편의 연구는 제외하였다. 중재결과 로는 음향학적 검사, 공기역학적 검사 또는 전기성문파형 검사를 사용한 경우만을 포함하여 그 외 검사(대상자 자가 음성평가, 청지 각적 음성평가, 후두내시경 검사, 자기공명영상, 컴퓨터단층촬영, 컴퓨터모델링 등)를 통해 중재효과를 살펴본 18 편의 연구는 제외 하였다. 본 메타분석에 포함하는 선정 과정과 포함 및 제외 기준은 Figure 1과 같다.

최종 선정된 18편의 연구에서 Guzman 등(2016)은 근긴장성발 성장애(muscle tension dysphonia, MTD)와 성대마비 환자를 대상 으로 하였고, $\operatorname{Kim}$ 등(2017)은 MTD, 성대결절, 성대폴립 환자를 대 상으로 SOVTE를 각각 실시하였기에 이를 각 2 개와 3 개로 구분하

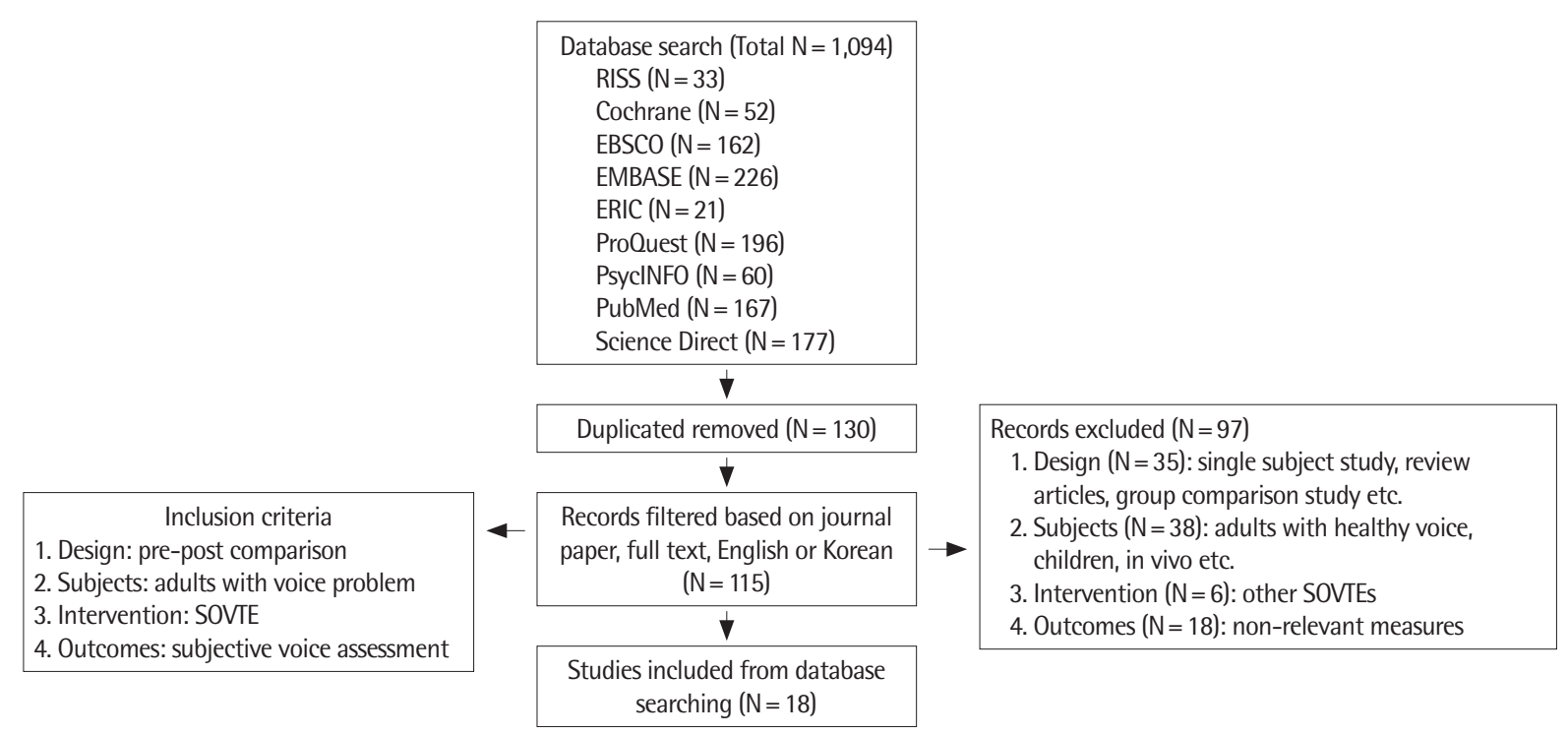

Figure 1. Flowchart of studies included from database search.

SOVTE = semi-occluded vocal tract exercise. 
였다. 또한 4편의 연구(Guzman et al., 2015, 2016, 2017, 2018)는 중 재방법이 2 가지 이상 사용되어 총 37 개로 구분하였다.

또한 중재결과 중 음향학적 검사의 항목으로 fundamental frequency (F0 in Hz), sound pressure level (SPL), \%jitter, \%shimmer, noise-to-harmonic ratio (NHR) 또는 harmonic-to-noise ratio ( $\mathrm{HNR}$ )와 공기역학적 검사는 subglottal pressure ( $\mathrm{Psub}$ in $\mathrm{cmH}_{2} \mathrm{O}$ ), phonation threshold pressure (PTP in $\mathrm{cmH}_{2} \mathrm{O}$ ), glottal airflow (L/ $\mathrm{sec})$, glottal resistance $\left(\mathrm{cmH}_{2} \mathrm{O} / \mathrm{L} / \mathrm{sec}\right)$ 을 분석에 포함하였다. 또한 전기성문파형 검사는 close quotient (CQ in \%)를 포함하였다. 중재 결과는 중재가 종료된 시점에서 측정된 결과만을 사용하였고, 중 재 도중이나 반복적으로 측정된 결과는 포함하지 않았다. 이에 본 연구에 최종적으로 선정된 분석대상은 18 편의 연구에서 37 개로 이 들에 대한 정보는 Appendix 1에 제시하였다.

\section{자료 코딩}

본 연구에 포함된 연구들을 연구자, 출판연도, 연구대상의 유형 및 표본수, 독립변인(SOVTE)의 하위 유형(TPA, WRT, 고음으로 불기, 입술떨기, 혀떨기, raspberry), 진동원의 수, 중재기간 및 횟수, 종속변인(음향학적, 공기역학적, 전기성문파형)의 영역별 통계값, 연구설계 등의 자료를 입력하였다. 각 종속변인의 통계값은 개별 연 구에서 제시된 평균(mean)과 표준편차(standard deviation)를 사 용하였고, 평균만 제시된 경우에는 평균과 사전-사후 간 차이에 대 한 유의확률( $p$ ) 값을 사용하였으며, 중위수(median)와 1 사분위수 와 3사분위수(1 \& 3 interquartiles)가 제시된 경우에는 Higgins와 Green (2008) 그리고 Wan, Wang, Liu와 Tong (2014)이 제시한 공 식을 통해 평균과 표준편차로 변환하여 입력하였다. 이와 더불어 사전-사후 비교연구에서 필요한 사전-사후 간 상관관계 계수는 보 수적으로.5로 입력하였다(Borenstein et al., 2009).

\section{자료 분석}

\section{효과크기 산출}

본 연구의 메타분석을 위해 Comprehensive Meta-Analysis 3 (CMA3; Biostat Inc., Englewood, NJ, USA)를 사용하였다. 음성장 애 대상자에게 SOVTE를 실시하기 전과 후에 산출된 음성의 차이 를 분석하기 위해 음향학적 검사(F0, SPL, \%jitter, \%shimmer, NHR or HNR), 공기역학적 검사(Psub, PTP, glottal airflow, glottal resistance) 및 전기성문파형 검사 $(\mathrm{CQ})$ 에 대한 각 검사 영역별 효과크기 를 분석한 후 영역별로 각 항목에 대한 효과크기를 개별적으로 분 석하였다.

SOVTE의 효과크기는 검사 영역별로 표준화된 평균 차이(stan- dardized mean difference)인 Cohen's $d$ 를 산출하였고, 각 연구의 표본수가 작을 경우 효과크기 $d$ 가 과대추정될 수 있어 표본이 큰 연구와 작은 연구들이 함께 섞여 있는 경우에 이를 교정해 주는 Hedges' $g$ 로 산출하는 것이 바람직하므로 본 연구에서도 모든 효 과크기를 Hedges' $g$ 로 전환하였다(as cited in Hwang, 2016). 또한 개별 효과크기를 평균한 평균효과크기는 연구 간의 표본크기를 고 려하여 가중평균효과크기(weight effect size)를 산출하였고, $95 \%$ 신뢰구간을 기준으로 유의수준 .05 를 사용하여 효과크기의 유의 성을 검증하였다.

개별 연구 효과크기들 간의 통계적 이질성 검정(statistical heterogeneity)을 실시한 결과, 음향학적 검사 $(Q=220.185, p<.001)$, 공기 역학적 검사 $(Q=277.522, p<.001)$, 전기성문파형 검사 $(Q=101.228$, $p<.001)$ 의 모든 검사 영역에서 이질적인 효과크기를 제시하고 있 어 표집오차 외에 추가로 오차 요인을 더한 무선효과모형(random effects model)을 사용하여 평균효과크기를 산출하였다(Borenstein et al., 2009).

\section{메타 ANOVA}

본 메타분석에 포함된 대상자들의 음성장애 유형(과다기능적, 성대폐쇄부전, 음도 이상)에 따른 SOVTE의 종속변인에 미치는 효 과크기 차이를 비교하고자 메타 ANOVA를 실시하였다.

\section{출판편향 검증}

메타분석 결과에 대한 타당성을 검증하기 위해 출판편향(publication bias)의 유무를 살펴보았다. 이를 위해 Funnel plot에서 시각 적으로 좌우대칭성을 확인하고, Egger 회귀분석(Egger's regression test)을 사용하여 통계적 대칭성을 분석하였다. 그 결과, 음향 학적 검사와 공기역학적 검사는 시각적 대칭성이 관찰되었고(Figures 2, 3), 음향학적 검사의 회귀식 초기값(intercept)은 -.011 ( $t=.013$, $d f=60, p=.990)$ 이었으며, 공기역학적 검사의 intercept는 $2.123(t=$ $1.905, d f=40, p=.063)$ 으로 통계적으로 유의하지 않아 음향학적 검사와 공기역학적 검사의 분석을 위해 선정된 논문들은 출판편향 이 없음을 확인하였다. 다만, 전기성문파형 검사 영역은 Funnel plot 에서 시각적 비대칭성이 관찰되었고, intercept가 $3.639(t=2.962$, $d f=23, p=.007$ )로 통계적으로 유의하게 나타났다(Figure 4). 따라 서 전기성문파형 검사를 위해 선정된 논문들은 출판편의의 오류가 있음을 알 수 있다. 오류의 정도를 살펴보기 위해 Rosenthal의 안전 성 계수(Fail-Safe N) 공식을 통해 산출된 안전성 계수가 144.000으 로(as cited in Hwang, 2016), Rosenthal의 N의 기준인 5k+10 (k: 연 구 수)보다 크게 나타나 대상연구 수에 비해 누락된 연구의 수가 많 


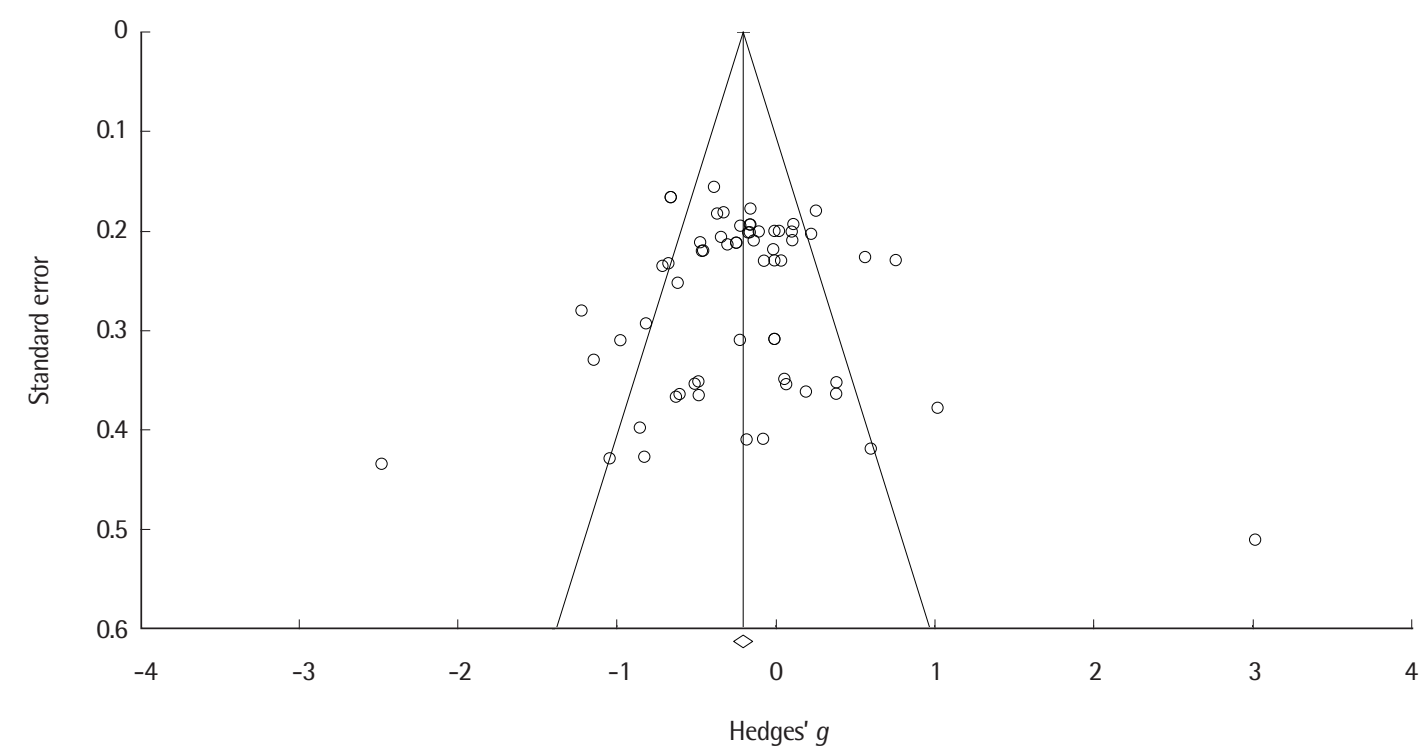

Figure 2. Funnel plot of standard error by Hedges' $g$ in acoustic analysis.

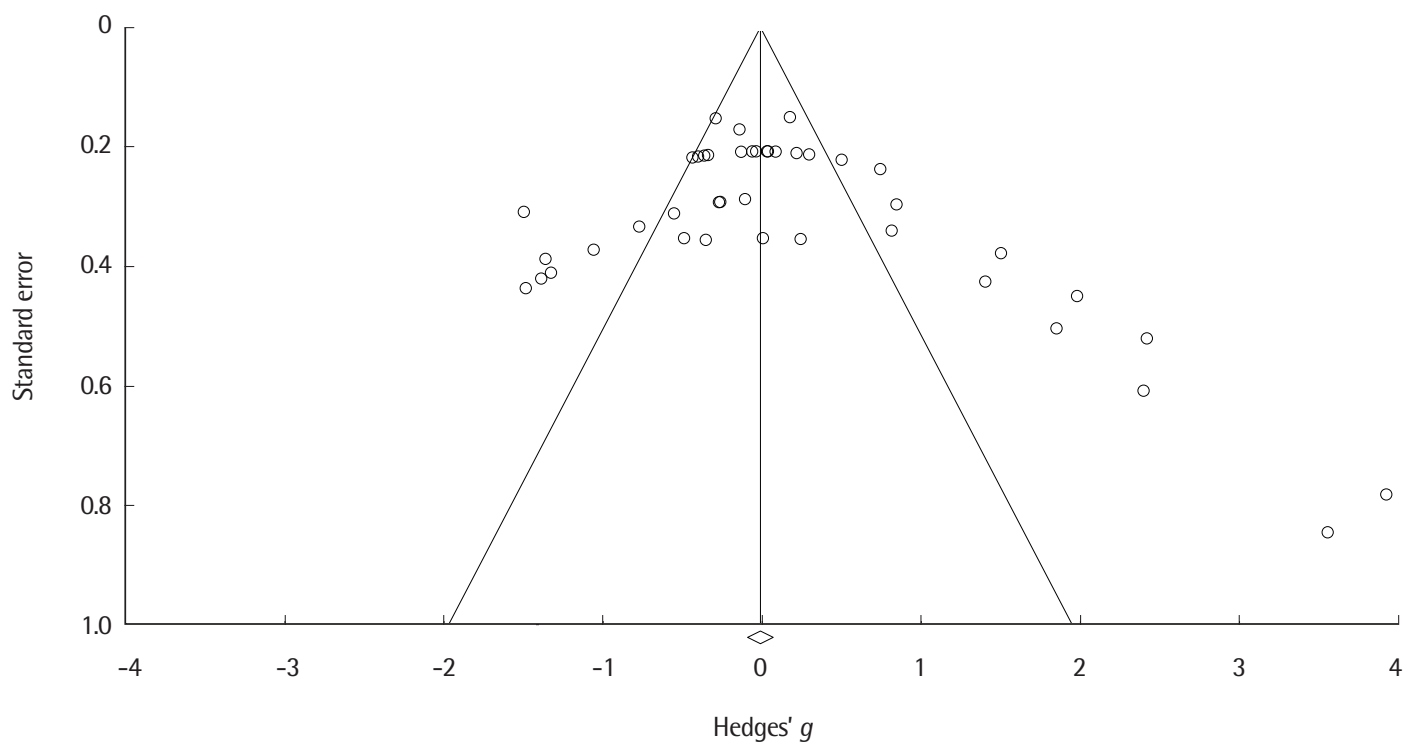

Figure 3. Funnel plot of standard error by Hedges' $g$ in aerodynamic analysis.

으므로 본 연구의 출판편향은 작은 수준임을 알 수 있다.

\section{대상 연구들의 질 평가}

본 연구를 위해 선정된 18 편 연구들의 질적 평가는 Gersten 등 (2005)의 필수 질적 지표(essential quality indicators)를 사용하여 실시하였다. 필수 질적 지표는 연구대상자에 대한 정보, 중재방법 과 통제 집단에 대한 정보, 측정 변인에 대한 정보, 자료 분석에 대 한 정보에 관한 10 항목으로 이루어졌으며, 각 항목을 3점 척도(1점
부적절, 2점 불명확, 3 점 적절)로 질적 수준을 평가하였다. 그 결과, 7편의 연구(Costa, Costa, Oliveira, \& Behlau, 2011; Denizoglu et al., 2018; Frisancho et al., 2018; Kim et al., 2017; Nam et al., 2018; Paes et al., 2013; Sielska-Badurek et al., 2017)가 중재방법에서 SOVTE 중재 시간이나 빨대발성의 경우 빨대의 특성(길이나 내부 직 경 또는 물속에 넣는 깊이)을 명확하게 제시하지 않았고, $\mathrm{F} 0$ 를 측정 변수로 포함한 연구들 중에서 3편의 연구(de Andrade et al., 2018; Frisancho et al., 2018; Guzman et al., 2017)가 대상자의 성별이 명 


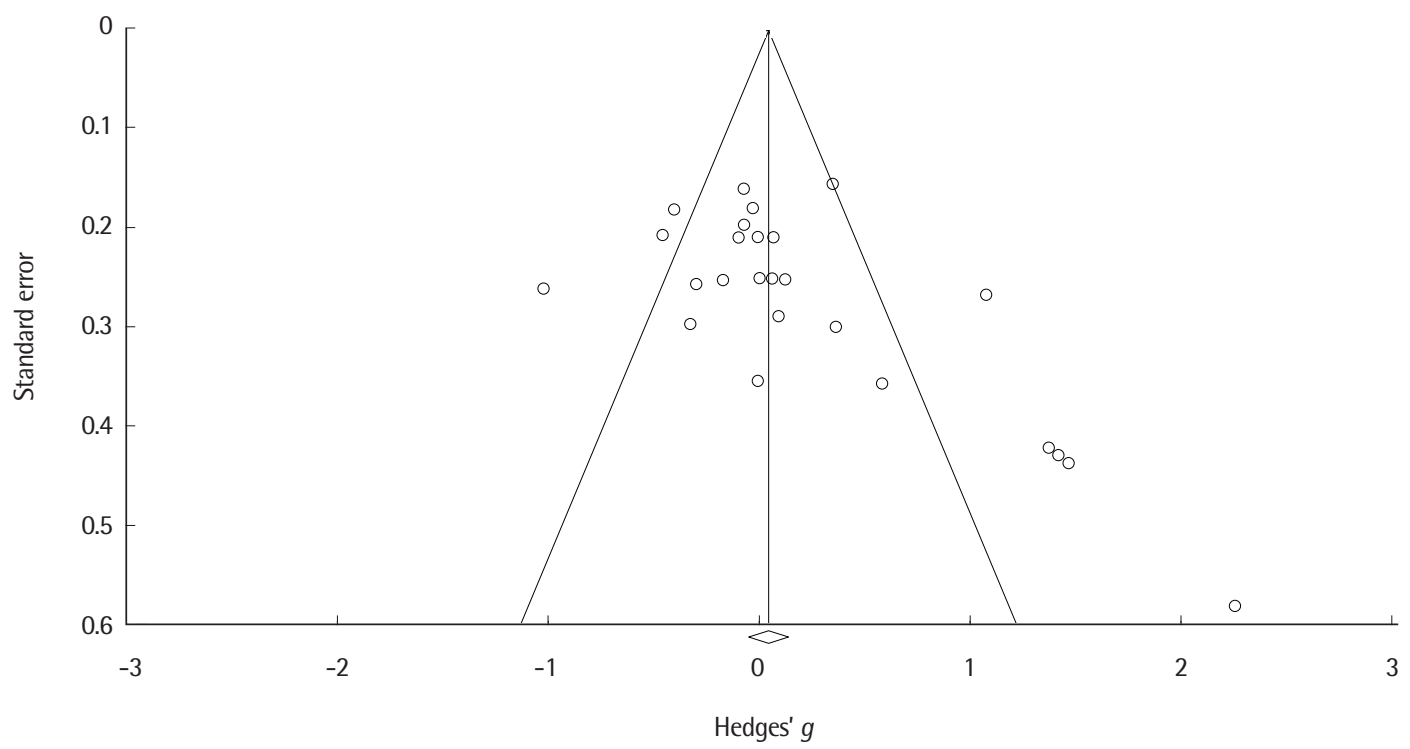

Figure 4. Funnel plot of standard error by Hedges' $g$ in electroglottographic analysis

확하게 제시되지 않았다. 이에 18 편의 연구의 평균은 2.91 (범위: 2.8-3.0)점으로 평가되었고, 모든 연구의 질적 수준은 적절한 것으 로 확인되었다.

\section{신뢰도 평가}

제1평가자가 선정한 연구들을 대상으로 음성장애 관련 임상경 력 및 교육경력이 10 년 이상인 언어병리학박사 1 명이 본 연구에 포 함하기 적합한 연구인지를 독립적으로 평가하였다. 적합성 여부는 본 연구에서 설정한 연구설계, 연구대상, 중재방법, 중재결과의 포 함기준에 부합하는지를 기준으로 적합 또는 부적합으로 평가하였 고, 그 결과, 두 연구자가 선정한 연구들이 일치하여 $100 \%$ 의 평가 자 간 신뢰도를 보였다. 또한 최종적으로 선정된 연구들의 $10 \%$ 에 해당하는 2 편의 연구를 무선적으로 선정하여 제 1 평가자가 데이터 를 입력한 후 효과크기를 산출하여 각 항목별 일치율을 살펴본 결 과 평가자 내 신뢰도도 $100 \%$ 를 보였다.

\section{연구결과}

\section{질적 분석}

\section{연구대상}

본 연구에서 분석대상으로 포함된 18편의 연구는 2011년부터 2018년도에 게재된 연구들로 2017년도와 2018년도에 집중적으로 게재되었다. 이들을 연구방법과 중재방법에 따라 37 개로 구분하여 분석한 결과, 집단 간 사전-사후 비교가 4 개, 집단 내 사전-사후 비
교가 33개였으며, 집단 내 사전-사후 비교연구 중 Menezes 등(2011) 의 연구는 실험군(27명)에게 SOVTE를 시행한 후 이들 중 일부(10 명)에게 위약훈련(placebo exercises)을 실시하여 비교한 것으로 집 단 내에서 반복 측정한 연구였다.

본 메타분석에서 분석한 총 대상자는 665 명으로, 각 연구별 대 상자는 최소 7 명부터 최대 42 명이었고, 평균연령은 34.36세였다. 집 단 간 사전-사후 비교연구에서 실험군 89 명의 평균연령은 35.05 세, 대조군 71 명의 평균연령은 30.74 세였으며, 집단 내 사전-사후 비교 연구의 대상자 515 명의 평균연령은 36.24 세였다. 연구대상자 모두 음성의 문제가 있었고, 음성문제는 크게 과다기능적 음성장애 (MTD, 성대결절, 성대폴립, 성대부종, 성대피로 등), 성대폐쇄부전 (성대마비, 성대틈[glottal gap] 등) 및 음도이상(성장호르몬결핍, 변 성발성장애)으로 구분되었다. 음성장애 중증도에 따라 SOVTE의 효과 차이가 나타날 수 있다. 이에 음성장애의 중증도를 구분하여 살펴보고자 하였으나 본 연구에서 분석한 연구들은 주로 청지각적 으로 중증도를 평가하였거나 또는 중증도를 명시하지 않은 경우가 많아 각 연구들의 중증도를 객관화시키는 것이 어려워 중증도에 따른 차이는 살펴보지 않았다.

\section{중재내용}

본 연구에서 분석대상의 SOVTE 하위 유형을 진동원의 수에 따 라 구분한 결과, 진동원의 수가 1 개인 경우는 17 개(TPA 15 개, 고음 으로 불기 2 개)였고, 2 개인 경우는 20 개-WRT 12 개, 입술떨기 4 개, 혀떨기 3개(단, Ribeiro 등(2019)의 연구에서는 입술떨기 또는 
혀떨기 중 한 가지 유형을 실시), raspberry 1개-였다. 각 연구의 SOVTE 중재내용은 Appendix 1에 제시하였다.

\section{중재결과}

18 편 연구에서 37 개 분석대상의 중재결과인 음향학적, 공기역학 적 및 전기성문파형 검사의 하위 항목을 살펴본 결과, $\mathrm{CQ}$ 가 25개로 가장 많았고, 그 다음으로 Psub가 19개, F0가 18개, \%jitter와 \%shimmer가 14 개의 순으로 많았다. 그리고 glottal airflow와 NHR은 9 개, PTP는 8개, SPL은 7개, glottal resistance가 6개였다. 단, Costa 등(2011)은 모든 음향학적 검사를 성별로 구분하여 따로 분석하였 고, Nam 등(2018)은 F0를 성별로 구분한 분석결과를 제시하였다. 중재결과는 Appendix 1에 제시하였다.

\section{메타분석 결과}

SOVTE가 음성장애의 음향학적 검사에 미치는 효과

SOVTE가 음성장애의 음향학적 검사에 미치는 효과를 메타분 석으로 분석한 결과는 Figure 5와같다. 효과크기 $g=-.208(p=.001)$, 95\% 신뢰구간[-.326, -.090]으로 SOVTE가 음성장애 대상자의 음 향학적 변수로 평가된 음성문제를 유의하게 감소시키는 것으로 나 타났다.

음향학적 검사의 각 하위 항목별 평균효과크기를 분석한 결과, F0와 SPL은 유의한 효과가 나타나지 않은 반면, \%jitter는 $g=-.231$ $(p=.026), \%$ shimmer는 $g=-.381(p<.001)$, NHR은 $g=-.427(p=$ .001)로 모두 유의하게 감소하여 SOVTE가 \%jitter, \%shimmer, NHR을 유의하게 감소시키는 데 효과가 있음을 알수 있다(Table 1).

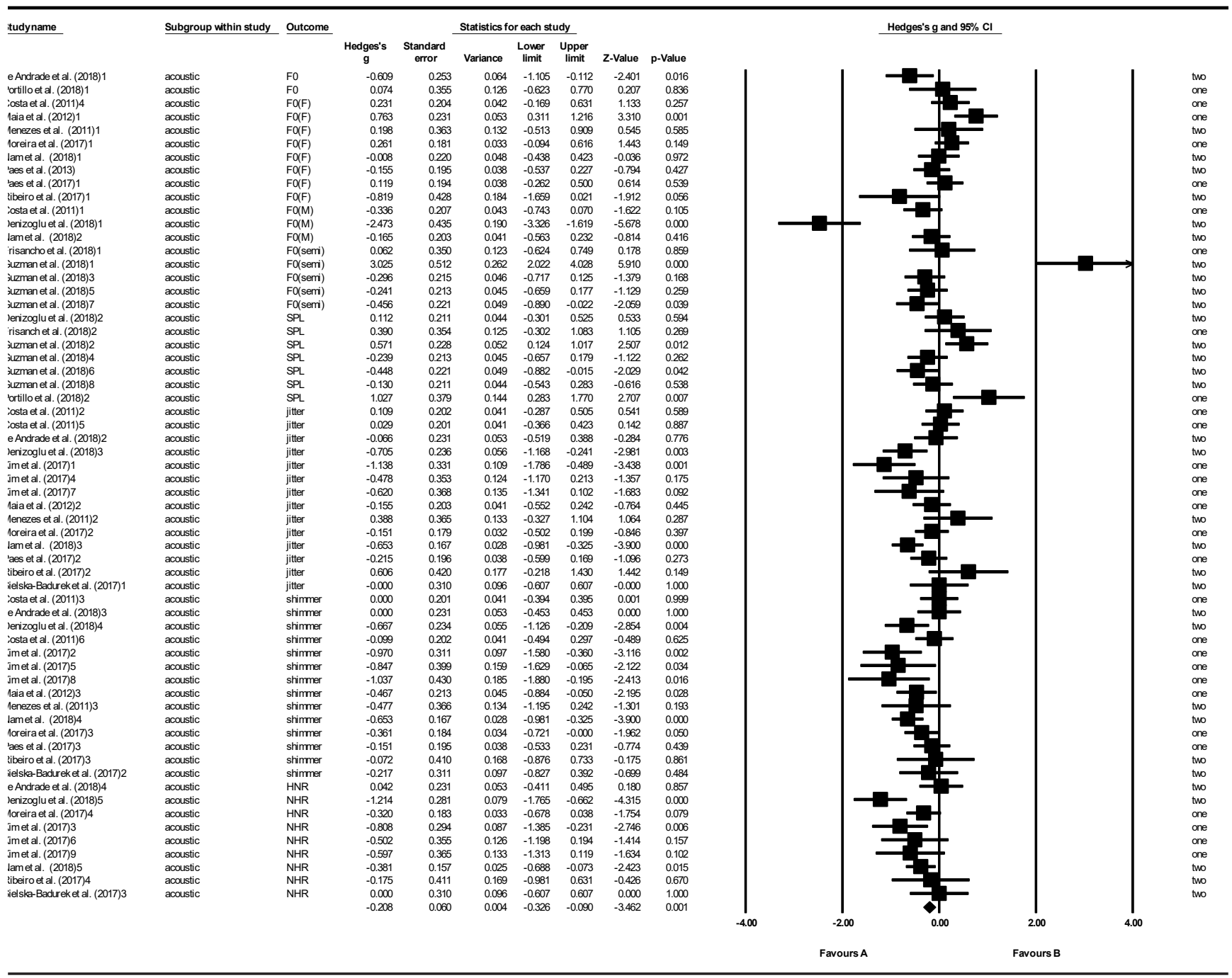

Figure 5. Meta-analysis of the effectiveness of SOVTE on acoustic analysis. SOVTE $=$ semi-occluded vocal tract exercise. 


\section{SOVTE가 음성장애의 공기역학적 검사에 미치는 효과}

SOVTE가 음성장애의 공기역학적 검사에 미치는 효과는 Figure 6과 같다. 공기역학적 검사에 대한 $g=.109(p=.326), 95 \%$ 신뢰구간 [-.109, .328]으로 SOVTE가 음성장애 대상자의 공기역학적 변수로 평가된 음성문제를 유의하게 감소시키지 않는 것으로 나타났다.

Table 1. The effectiveness of SOVTE on acoustic analysis for the patients with voice disorders

\begin{tabular}{lcccc}
\hline \multirow{2}{*}{ Subcategory } & \multirow{2}{*}{ Effect size $(g)$} & \multicolumn{2}{c}{$95 \% \mathrm{Cl}$} & \\
\cline { 3 - 4 } & & Lower limit & Upper limit & \\
\hline F0 (Hz) & -.065 & -.345 & .216 & .651 \\
SPL (dB) & .127 & -.211 & .465 & .461 \\
\%Jitter (\%) & -.231 & -.435 & -.027 & .026 \\
\%Shimmer (\%) & -.381 & -.551 & -.210 & $<.001$ \\
NHR & -.427 & -.676 & -.177 & .001 \\
\hline
\end{tabular}

SOVTE= semi-occluded vocal tract exercise; $\mathrm{Cl}=$ confidence interval; $\mathrm{FO}=$ fundamental frequency; $\mathrm{SPL}=$ sound pressure level; $\mathrm{NHR}=$ noise-to-harmonic ratio.
그러나 공기역학적 검사의 각 하위 항목별로 구분하여 살펴본 결과, Psub는 $g=.738$ ( $p=.001)$ 로 유의하게 증가하였고, PTP는 $g=$ -.622 ( $p=.017)$, glottal resistance $g=-.256$ ( $p=.011)$ 으로 유의하게 감소하여 SOVTE가 이 세 항목에 대해 유의한 효과를 나타냈음을 알 수 있다. 다만, glottal airflow는 SOVTE 실시 전과 후에 유의한 차이가 없었다. Table 2에 SOVTE의 공기역학적 검사에 미치는 효

Table 2. The effectiveness of SOVTE on aerodynamic analysis for the patients with voice disorders

\begin{tabular}{|c|c|c|c|c|}
\hline \multirow{2}{*}{ Subcategory } & \multirow{2}{*}{$\begin{array}{c}\text { Effect size } \\
(g)\end{array}$} & \multicolumn{2}{|c|}{$95 \% \mathrm{Cl}$} & \multirow{2}{*}{$p$-value } \\
\hline & & Lower limit & Upper limit & \\
\hline Psub $\left(\mathrm{cmH}_{2} \mathrm{O}\right)$ & .738 & .304 & 1.172 & .001 \\
\hline PTP $\left(\mathrm{cmH}_{2} \mathrm{O}\right)$ & -.622 & -1.133 & -.111 & .017 \\
\hline Glottal airflow (L/sec) & .028 & -.276 & .331 & .858 \\
\hline Glottal resistance $\left(\mathrm{cmH}_{2} \mathrm{O} / \mathrm{L} / \mathrm{sec}\right)$ & -.256 & -.452 & -.060 & .011 \\
\hline
\end{tabular}

SOVTE= semi-occluded vocal tract exercise; $\mathrm{Cl}=$ confidence interval; $P$ sub = subglottal pressure; PTP= phonation threshold pressure.

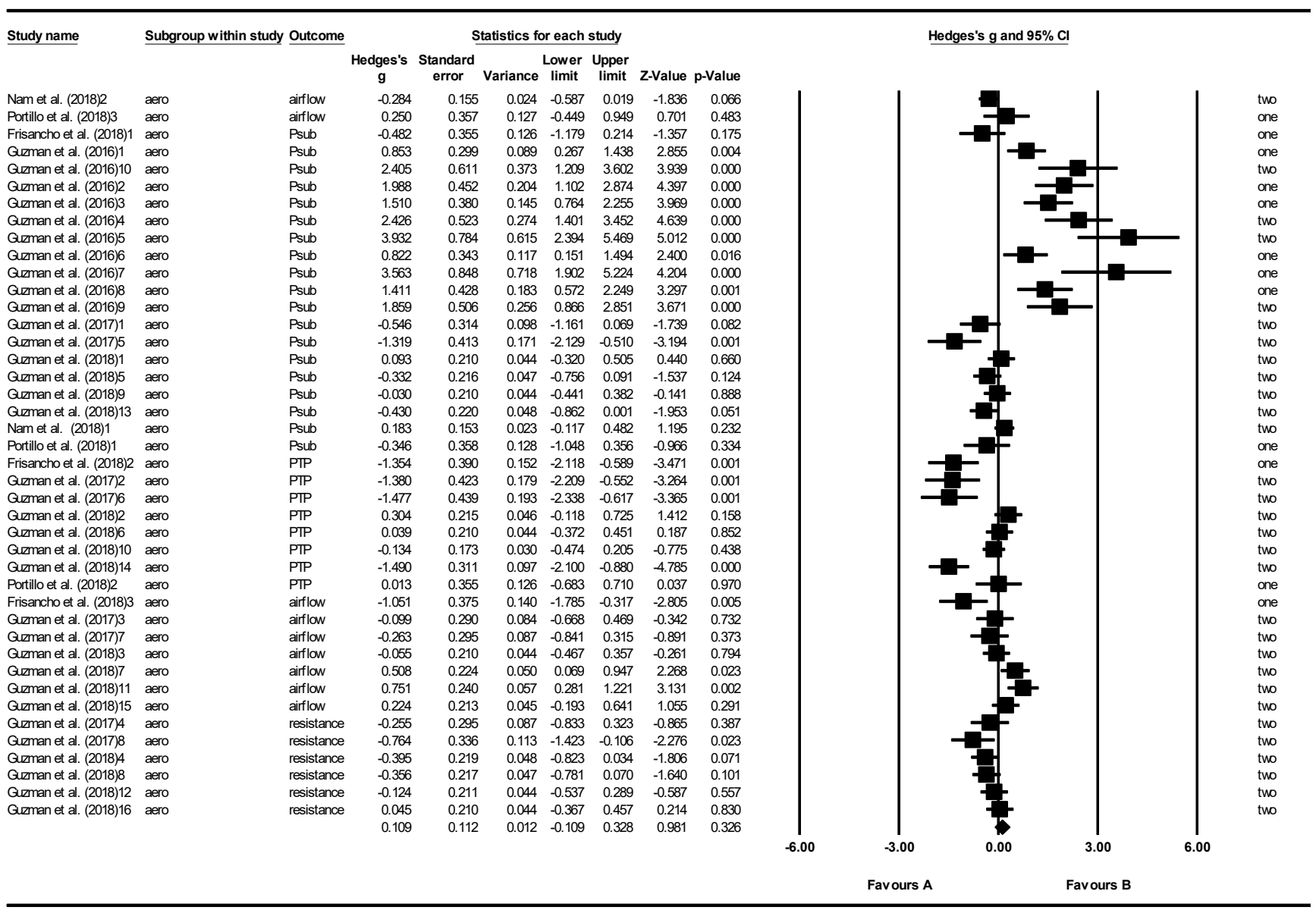

Figure 6. Meta-analysis of the effectiveness of SOVTE on aerodynamic analysis.

SOVTE $=$ semi-occluded vocal tract exercise. 
과크기를 제시하였다.

SOVTE가 음성장애의 전기성문파형 검사에 미치는 효과

SOVTE가 음성장애의 전기성문파형 검사에 미치는 효과를 살 펴보기 위해 실시한 $\mathrm{CQ}$ 에 대한 메타분석 결과는 Figure 7에 제시 하였다. SOVTE의 CQ에 대한 $g=.153$ ( $p=.136), 95 \%$ 신뢰구간 $[-.048, .355]$ 으로 SOVTE가 음성장애 대상자의 $\mathrm{CQ}$ 를 유의하게 변 화시키지 않는다는 것을 알 수 있다.

\section{음성장애 유형에 따른 종속변인에 대한 효과크기 차이}

음성장애 유형에 따라 음향학적, 공기역학적 및 전기성문파형 검 사에 대한 SOVTE의 효과크기 차이를 비교하기 위해 실시한 메타 ANOVA 결과, 음향학적 검사에서 과다기능적 음성장애, 성대폐쇄 부전 및 음도이상 집단의 $g$ 는 각 - .124 ( $p=.059),-.397$ ( $p=.001)$, -.556 ( $p=.007)$ 으로 성대폐쇄부전과 음도이상 집단의 경우는 SOVTE가 음향학적 검사에서 유의하게 음성문제를 감소시키는 효과가 있었지만 과다기능적 음성장애 집단은 SOVTE가 음향학 적 검사 결과에 영향을 미치지 않아 세 집단 간에도 통계적으로 유 의한 차이를 보였다 $(Q=6.891, p=.032)$.

음향학적 검사의 하위 항목별로 살펴본 결과, \%jitter는 과다기능 적 음성장애와음도이상 집단에서 SOVTE에 의한 유의한 효과가 없
었지만 성대폐쇄부전 집단의 $g=-.653(p<.001)$ 으로 유의하게 감소 하였으며, 세 집단간에 유의한차이를 보였다 $(\mathrm{Q}=6.538, p=.038) . \mathrm{F} 0$, $\mathrm{SPL}$ \% $\%$ himmer 및 NHR은 집단 간에 유의한 차이를 보이지는 않았 지만 \%shimmer는 과다기능적 음성장애 집단의 $g=-.344$ ( $p<.001)$, 성대폐쇄부전 집단의 $g=-.653$ ( $p<.001)$ 으로 SOVTE 실시 후 두 집 단의 \%shimmer가 유의하게 감소하였고, 음도이상 집단에서는 유의 한 효과가 없었다. NHR은 과다기능적 음성장애 집단에서 $g=-388$ ( $p=.001)$, 성대폐쇄부전 집단에서 $g=-.381$ ( $p=.015)$ 로 유의하게 감 소하였으나음도이상 집단에서는 유의한차이가 없었다.

공기역학적 검사는 음도이상 집단을 대상으로 실시한 연구가 없 었기 때문에 과다기능적 음성장애와 성대폐쇄부전 집단 간의 차이 만 분석한 결과, 성대폐쇄부전 집단은 $g=1.186$ ( $p=.001)$ 으로 SOVTE 실시 후 공기역학적 검사에서 유의한 효과가 나타난 반면 과다기능적 음성장애 집단은 효과가 없었으며, 두 집단 간의 차이 는 유의하게 나타났다 $(Q=10.400, p=.001)$.

공기역학적 검사의 하위 항목별로 음성장애 유형에 따른 효과크 기를 비교한 결과, Psub는 성대폐쇄부전 집단에서만 SOVTE에 의 해 유의하게 증가하였고 $(g=1.533, p=.001)$ 과다기능적 음성장애 집단에서는 유의한 효과가 없었으며, 두 집단 간에는 유의한 차이 가 있었다 $(Q=4.558, p=.033)$. Glottal airflow는 모든 음성장애 집 단에서 유의한 효과가 나타나지 않았으며, 두 집단 간에도 유의한

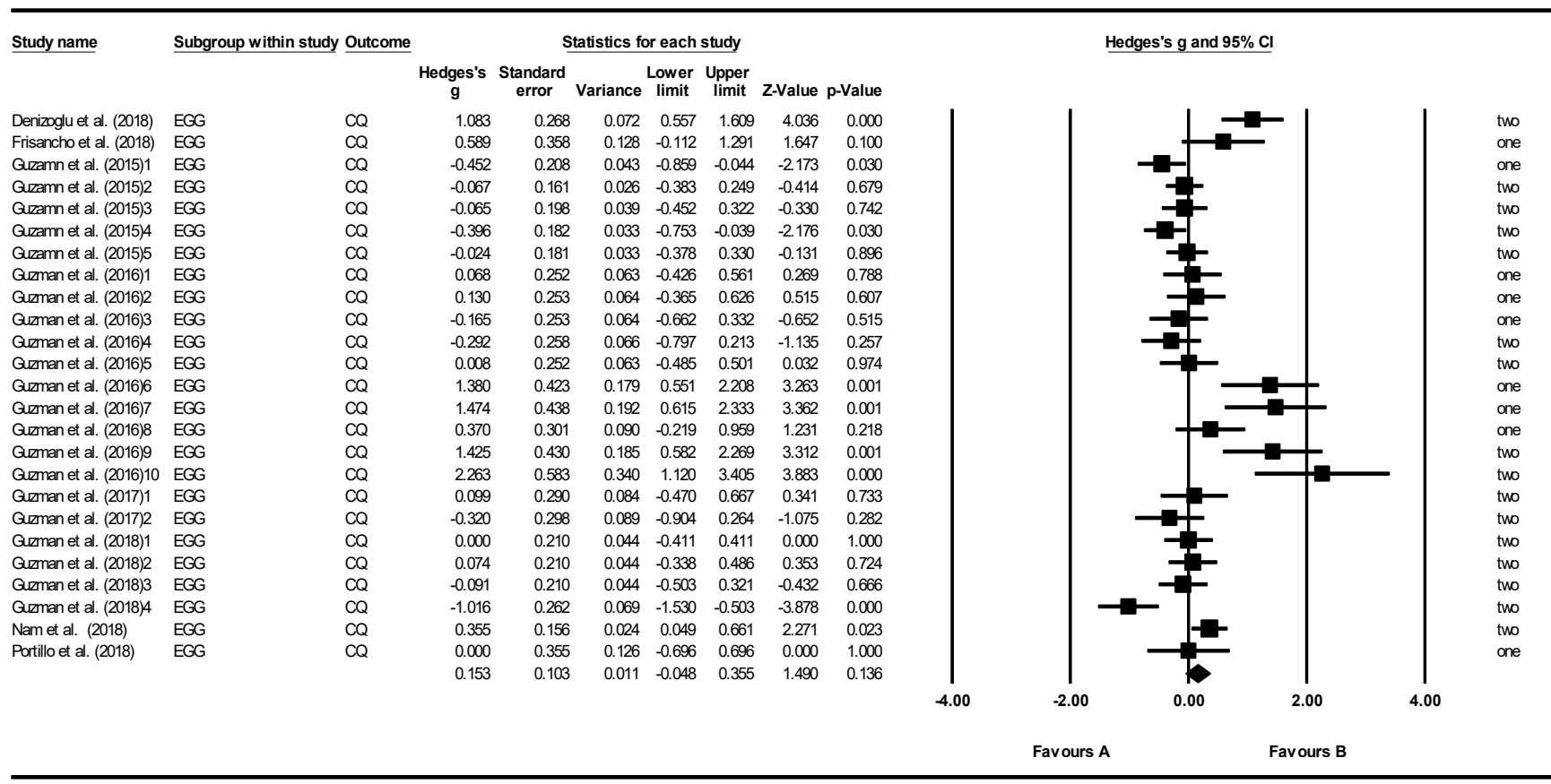

Figure 7. Meta-analysis of the effectiveness of SOVTE on electroglottographic analysis.

SOVTE $=$ semi-occluded vocal tract exercise. 
Table 3. Difference in effect sizes of SOVTE by types of voice disorders

\begin{tabular}{|c|c|c|c|c|c|c|c|}
\hline \multirow{2}{*}{ Subcategory } & \multirow{2}{*}{$\begin{array}{l}\text { Type of voice disorders } \\
\text { (analyzed \#) }\end{array}$} & \multirow{2}{*}{$\begin{array}{l}\text { Effect size } \\
\qquad(g)\end{array}$} & \multicolumn{2}{|c|}{$95 \% \mathrm{Cl}$} & \multirow{2}{*}{$p$-value } & \multicolumn{2}{|c|}{ Meta ANOVA } \\
\hline & & & Lower limit & Upper limit & & 0 & $p$-value \\
\hline \multirow[t]{3}{*}{ Acoustic } & Hyperfunctional (48) & -.124 & -.252 & .004 & .059 & 6.891 & .032 \\
\hline & Glottal gap (5) & -.397 & -.635 & -.159 & .001 & & \\
\hline & Abnormal pitch (9) & -.556 & -.961 & -.150 & .007 & & \\
\hline \multirow[t]{3}{*}{$\mathrm{FO}(\mathrm{Hz})$} & Hyperfunctional (14) & .102 & -.186 & .390 & .488 & 3.471 & .176 \\
\hline & Glottal gap (2) & -.093 & -.385 & .199 & .534 & & \\
\hline & Abnormal pitch (2) & -1.507 & -3.333 & -.318 & .106 & & \\
\hline \multirow[t]{2}{*}{$\mathrm{SPL}(\mathrm{dB})$} & Hyperfunctional (6) & .141 & -.270 & .552 & .502 & .009 & .924 \\
\hline & Abnormal pitch (1) & .112 & -.301 & .525 & .594 & & \\
\hline \multirow[t]{3}{*}{ \%Jitter (\%) } & Hyperfunctional (11) & -.143 & -.359 & .070 & .192 & 6.538 & .038 \\
\hline & Glottal gap (1) & -.653 & -.981 & -.325 & $<.001$ & & \\
\hline & Abnormal pitch (2) & -.383 & -1.200 & .243 & .230 & & \\
\hline \multirow[t]{3}{*}{ \%Shimmer (\%) } & Hyperfunctional (11) & -.344 & -.531 & -.156 & $<.001$ & 2.633 & .268 \\
\hline & Glottal gap (1) & -.653 & -.981 & -.325 & $<.001$ & & \\
\hline & Abnormal pitch (2) & -.333 & -.997 & .321 & .319 & & \\
\hline \multirow[t]{3}{*}{ NHR } & Hyperfunctional (6) & -.388 & -.617 & -.159 & .001 & .092 & .955 \\
\hline & Glottal gap (1) & -.381 & -.688 & -.073 & .015 & & \\
\hline & Abnormal pitch (2) & -.576 & -1.806 & .654 & .359 & & \\
\hline \multirow[t]{2}{*}{ Aerodynamic } & Hyperfunctional (35) & -.060 & -.286 & .166 & .605 & 10.400 & .001 \\
\hline & Glottal gap (7) & 1.186 & .464 & 1.909 & .001 & & \\
\hline \multirow[t]{2}{*}{ Psub $\left(\mathrm{cmH}_{2} \mathrm{O}\right)$} & Hyperfunctional (13) & .421 & -.094 & .935 & .109 & 4.558 & .033 \\
\hline & Glottal gap (6) & 1.533 & .651 & 2.415 & .001 & & \\
\hline $\mathrm{PTP}\left(\mathrm{cmH}_{2} \mathrm{O}\right)$ & Hyperfunctional (8) & -.622 & -1.133 & -.111 & .017 & - & - \\
\hline \multirow[t]{2}{*}{ Glottal airflow (L/sec) } & Hyperfunctional (8) & .077 & -.255 & .409 & .649 & 2.478 & .115 \\
\hline & Glottal gap (1) & -.284 & -.587 & .019 & .066 & & \\
\hline Glottal resistance $\left(\mathrm{cmH}_{2} \mathrm{O} / \mathrm{L} / \mathrm{sec}\right)$ & Hyperfunctional (6) & -.256 & -.452 & -.060 & .011 & - & - \\
\hline \multirow[t]{3}{*}{$\mathrm{CO}(\%)$} & Hyperfunctional (18) & -.124 & -.256 & .007 & .064 & 33.332 & $<.001$ \\
\hline & Glottal gap (6) & 1.905 & .514 & 1.676 & $<.001$ & & \\
\hline & Abnormal pitch (1) & 1.083 & .557 & 1.609 & $<.001$ & & \\
\hline
\end{tabular}

SOVTE= semi-occluded vocal tract exercise; $\mathrm{Cl}=$ confidence interval; $\mathrm{FO}=$ fundamental frequency; $\mathrm{SPL}=$ sound pressure level; NHR=noise-to-harmonic ratio; Psub=subglottal pressure; PTP= phonation threshold pressure.

차이가 없었다. PTP와 glottal resistance는 과다기능적 음성집단에 서만 측정이 되어 음성장애 유형 간차이를 비교하지 못했다.

전기성문파형 검사를 통해 측정된 $\mathrm{CQ}$ 를 음성장애 유형 간에 비 교한 결과, 과다기능적 음성장애 집단은 SOVTE가 CQ에 미치는 효과가유의하지 않은 반면, 성대폐쇄부전 집단의 $g=1.905$ ( $p<.001$ ), 음도이상 집단의 $g=1.083$ ( $p<.001)$ 으로 SOVTE가 두 집단의 CQ 를 유의하게 증가시켰으며, 세 집단 간에 효과크기의 차이는 유의 하게 나타났다 $(Q=33.332, p<.001)$ (Table 3).

\section{논의 및 결론}

본 연구는 SOVTE가 음성장애 대상자에게 음향학적, 공기역학 적 및 전기성문파형 검사에서 유의한 효과가 있는지를 종합적으로
분석하고자 메타분석을 이용하여 체계적인 문헌고찰을 실시하였 다. 동료심사에 의해 2011년부터 2018년까지 학술지에 게재된 영문 과 국문으로 작성된 연구를 중심으로 선정 기준에 부합하는 총 18 편의 연구를 음성장애 유형과 SOVTE 기법에 따라 37 개로 구분하 여 분석하였다. 음성장애 유형은 크게 과다기능적 음성장애, 성대 폐쇄부전, 음도이상으로 구분되었고, 중재방법으로는 SOVTE 기 법 중에서 WRT, TPA, 입술떨기, 혀떨기, raspberry가 포함되었다. 중재결과로 전기성문파형 검사의 $\mathrm{CQ}$ 가 가장 많이 분석되었고, 음 향학적 검사는 Fo, SPL, \%jitter, \%shimmer 및 NHR, 공기역학적 검 사는 Psub, PTP, glottal airflow, glottal resistance를 포함하였다.

음향학적 검사에서 나타난 SOVTE의 중재효과를 살펴보면, 효 과크기가 -.208로 통계적으로 유의하게 나타나 Lipsey와 Wilson (2001)이 제시한 효과크기의 정도 기준에서 SOVTE를 실시한 후에 
음성문제가 작은 정도이지만 유의하게 감소하였음을 알 수 있다. 또한 음향학적 검사의 하위 항목인 \%jitter, \%shimmer 및 NHR의 음향학적 변수에서도 약함에서 중간 정도의 유의한 음의 효과크 기를 보여 SOVTE가 음질을 개선하는 데 효과가 있었다. SOVTE는 성도를 부분적으로 폐쇄하여 발성함으로써 구강 내 압력을 증가시 켜 이로 인해 발생하는 역압 $\left(\mathrm{P}_{\mathrm{back}}\right)$ 을 통해 성문을 발성 역치(phonation threshold) 조건에 부합하는 상태가 되도록 도울 뿐 아니라 배음들의 진폭을 상승시킨다(Laukkanen et al., 2008; Robieux, Galant, Lagier, Legou, \& Giovanni, 2015; Titze \& Laukkanen, 2007; Titze \& Story, 1997). 즉 SOVTE를 실시할 때 성대는 보다 원활하고 규칙 적으로 진동하여 음성효율성이 증가하고 음질은 개선된다는 사실 이 음향학적 검사에 대한 메타분석을 통해 입증이 되었다.

음향학적 검사에서 음성장애 유형에 따라 SOVTE에 따른 중재 효과의 차이가 있는지를 살펴본 결과, 성대폐쇄부전 집단에서 큰 정도의 효과크기(-.653)로 \% jitter가 유의하게 감소하였고, \%shimmer와 NHR이 과다기능적 음성장애 집단에서는 중간 정도의 효 과크기(-.344)와 성대폐쇄부전 집단에서는 큰 정도의 효과크기 (-.653)가 유의하게 나타났으나 음도이상 집단에서는 어떠한 음향 학적 변수도 유의한 변화가 없었다. 이러한 음성장애 유형에 따른 차이는 MTD, 성대결절 또는 성대폴립과 같은 과다기능적 음성장 애나 성대마비나 성대구증과 같은 성대폐쇄부전이 있는 대상자들 은 성대가 불규칙하게 진동하거나 성대의 접촉이 정상적으로 이루 어지지 않기 때문에 음질이 나쁜 반면 변성발성장애나 호르몬장애 로 인한 음도이상 집단에서는 음도를 제외한 음질은 정상적일 수 있기 때문에 나타난 현상이라고 볼 수 있다. 즉 SOVTE는 성대 진 동을 보다 규칙적이고 정상적인 양상으로 변화시키는 데 도움을 주 기 때문에 성대가 불규칙하게 진동하는 경우에 효과적이라고 할 수 있다. 다만, 음도이상 집단에서 SOVTE가 음도에 미치는 영향이 유의하게 나타나지 않은 것은 2 개의 연구만이 분석에 포함되었기 때문일 것이다. 두 연구를 각각 살펴보면, 21 명의 변성발성장애 남 성 집단을 대상으로 한 Denizoglu 등(2018)의 연구에서는 F0의 평 균이 $211.9 \mathrm{~Hz}$ 였다가 SOVTE 실시 이후에 $138.5 \mathrm{~Hz}$ 로 유의하게 감 소하여 대조군의 $\mathrm{F} 0$ 인 $134.7 \mathrm{~Hz}$ 와 유사한 정도로 낮아져 SOVTE 의 효과가 크게 나타난 반면, 17 명의 성장호르몬결핍 환자를 대상 으로 한 de Andrade 등(2018)의 연구에서는 SOVTE 실시 전에 F0 의 평균이 $196.91 \mathrm{~Hz}$ 였다가 실시 후에 $173.39 \mathrm{~Hz}$ 로 다소 감소하였 으나 통계적으로는 유의하지 않았다. 이에 본 연구의 메타분석 결 과에서는 잘 나타나지 않았지만 SOVTE가 음도이상 집단에서 F0 에도 영향을 미칠 수 있음을 추측할 수 있다. 추후에는 음도이상 집 단뿐 아니라 음성장애로 인해 음도의 변화가 나타난 집단을 대상
으로 SOVTE가 음도에 미치는 영향에 대해 좀 더 면밀히 살펴보는 연구가 진행될 필요가 있다.

공기역학적 검사의 하위 항목들을 종합적으로 살펴본 결과, SO$\mathrm{VTE}$ 의 공기역학적 검사에 대한 효과는 유의하지 않았다. 그러나 각 하위 항목별로 구분하였을 때, Psub와 PTP는 각 .738과 -.622로 큰 정도의 유의한 효과크기를 보였고, glottal resistance는 -.256의 작은 정도의 유의한 효과크기가 나타났다. SOVTE를 실시한 후에 Psub는 상당히 높아진 반면, PTP와 glottal resistance는 낮아졌음 을 알수 있다. 특히 Psub의 유의한 상승은 성대폐쇄부전 대상자들 에 의해 주로 이루어졌고, 유의하게 낮아진 PTP와 glottal resistance 는 과다기능적 음성장애 대상자들에서 나타났다. 즉 SOVTE의 효 과로 호흡 조절 능력이 향상되고 폐로부터의 기류가 증가하면서 Psub가 상승한 것은 성대접촉이 잘 이루어지지 않는 성대폐쇄부전 집단에서 1.533 의 큰 정도의 효과크기를 보여 성대의 폐쇄를 돕기 위한 호흡 조절이 이들 집단에서 더 활성화되었음을 알 수 있다 (Cordeiro et al., 2012; Gaskill \& Quinney, 2012). 과다기능적 음성 장애 집단에서는 SOVTE로 인해 증가된 상부 성도의 압력이 성대 에 가해지는 역압 $\left(\mathrm{P}_{\mathrm{back}}\right)$ 을 상승시켜 성도의 음향학적 임피던스가 높아지고, 이것이 성대의 임피던스와 성문 기류에 영향을 미쳐 발 성을 시작하고 유지하는 데 필요한 PTP는 감소한다(Bele, 2005; Story et al., 2000). 또한 증가된 구강 내 압력이 성대의 상부에 작용 하여 성대를 약간 외전된 상태로 유지시키기 때문에 성문저항은 다소 감소되어 성대 진동 시 성대의 충돌력이 감소한다(Croake, Andreatta, \& Stemple, 2017; Titze, 1988, 2014). 특히 본 연구에서 PTP와 glottal resistance는 과다기능적 음성장애 집단이 포함된 연 구에서만 분석되었기 때문에 성대가 과도하게 긴장하거나 접촉하 는 음성장애의 경우 SOVTE에 의해 과도한 긴장이나 접촉을 감소 시켜 성대 진동이 보다 효율적으로 이루어질 수 있음을 보여준다. 다만, glottal airflow는 음성장애 유형 모두에서 유의한 효과가 나 타나지 않아 성문 사이의 기류 흐름은 큰 변화가 없음을 알 수 있 다. 본 연구에서는 성대폐쇄집단이나 음도이상 집단에서는 PTP와 glottal resistance가 측정되지 않아 이들의 SOVTE에 따른 변화를 살펴볼 수 없었으므로 추후에는 성대폐쇄가 잘 이루어지지 않는 과소기능적 음성장애 집단이나 음도이상 집단에서의 PTP와 glottal resistance 등의 공기역학적 변수들이 SOVTE 실시 후 어떻게 변 화하는지를 살펴볼 필요가 있다.

전기성문파형 검사에서 측정된 $\mathrm{CQ}$ 는 전체 음성장애 유형을 대 상으로 분석했을 때 유의한 효과가 없었으나 음성장애 유형별로 구분했을 때, 발성 시 성대의 틈이 발생하는 성대폐쇄부전 집단과 음도이상 집단에서 $\mathrm{CQ}$ 의 효과크기가 각 1.905 와 1.083 으로 큰 정 
도의 효과가 나타났고, 과다기능적 음성장애 집단에서는 유의한 효과가 없었다. 이러한 결과는 SOVTE로 인해 증가된 구강 내 압력 은 성대를 약간 외전된 상태로 유지하고 $\mathrm{CQ}$ 는 감소시킨다는 선행 연구들(Andrade et al., 2016; Andrade et al., 2014; Bele, 2005; Croake et al., 2017; Gaskill \& Erickson, 2008; Hamdan et al., 2012) 과는 다른 결과이다. 이 연구들은 모두 음성장애가 없는 건강한 일 반인을 대상으로 한 연구로 본 메타분석에 포함된 대상자들과는 다른 발성 역학 메커니즘을 갖기 때문에 그러한 차이를 보일 수 있 다. 그러나 이 연구들에서도 $\mathrm{CQ}$ 의 범위 $\left(\mathrm{CQ}_{\mathrm{r}}\right)$ 는 대부분 증가하여 성대 진동 시 성대 진폭이 커진다는 것을 알 수 있다(Croake et al., 2017; Gaskill \& Erickson, 2008; Hamdan et al., 2012). 즉음성장애 대상자에게 SOVTE를 적용하였을 때 호흡조절 능력을 향상시키면 서 상승된 구강 내 역압 $\left(\mathrm{P}_{\mathrm{back}}\right)$ 이 성대에 가해져 성대와 내후두근들 을 보다 균형 잡힌 위치로 정렬시킴으로써 성대의 진동을 원활하게 도울 뿐 아니라 성문하압을 상승시켜 성대 가장자리의 진폭을 증가 시키며, 성도와 성대에 마사지 효과를 가져와 성대의 혈류를 원활 하게 증가시켰기 때문으로 보인다(Gaskill \& Quinney, 2012; Mendes et al., 2018). Nam 등(2018)의 연구에서 SOVTE로 증가된 구강 내 압력은 성대에 가해지는 역압을 증가시키고 이로 인해 glottal resistance는 감소하면서 성대가 살짝 벌어지지만 전반적인 성대의 접촉은 효율적으로 향상시킴으로써 $\mathrm{CQ}$ 가 증가하였고, 그 결과 최대발성시간이 증가하였다. Lee 등(2017)의 연구에서도 수정 된 입술트릴을 이용하여 SOVTE를 적용하였을 때 성대의 무리한 접촉은 감소하고 성대근이 이완된 상태를 유지하되 성문의 틈이 생기는 것은 감소한다고 하였다. 특히 SOVTE의 유형과 airflow resistance의 정도에 따라서 $\mathrm{CQ}$ 는 더욱 증가할 수 있다. TPA나 WRT 의 경우 빨대의 직경이 좁아질수록, 그리고 빨대를 물 속에 더 깊이 넣을수록 airflow resistance는 더욱 상승하고 구강 내 압력은 더욱 증가하며, 이로 인해 CQ는 더욱 상승한다(Andrade et al., 2014, 2016; Guzman et al., 2015). 다만, 음성장애가 있는 대상자들에서 측정되는 $\mathrm{CQ}$ 값은 이들이 나타내는 비주기적인 성대 진동으로 인 해 때로는 정확하게 측정하기 어려울 수 있기 때문에 SOVTE 중재 효과를 해석할 때 다른 평가결과와 함께 종합적으로 분석해 볼 필 요는 있다.

이러한 연구결과를 종합해 볼 때, SOVTE는 성대의 과도한 긴장 이나 스트레스와 신체적인 노력은 감소시키고, 성대 진동 시 성대 를 이완시켜 강한 접촉(glottal attack)은 감소시키지만 성대의 접촉 면적은 넓혀 전반적으로 성대 접촉의 효율성을 증대시킴으로써 음 성산출을 최대화한다고 할 수 있다(Croake et al., 2017; Mendes et al., 2018; Nam et al., 2018). 따라서 SOVTE는 후두의 내·외근에 과
도한 긴장이나 힘을 주는 과다기능적 음성장애(hyperkinetic dysphonia)나 성대의 틈이 발생하는 성대폐쇄부전 음성장애 모두에 서 유용하게 적용될 수 있다(as cited in Simberg \& Laine, 2007).

본 연구에 포함된 대상자들은 과다기능적 음성장애가 14편, 성 도폐쇄부전이나 음도이상은 각 2 편이었고, 분석된 중재방법의 개 수가 각 28개, 6 개, 2 개로 음성장애 유형에 따른 SOVTE의 효과의 차이를 명확하게 보여주었다고는 하기 어렵다. 이에 추후 SOVTE 관련 연구들이 더욱 활발히 이루어지면 보다 많은 연구를 대상으 로 추가적인 분석을 통해 본 연구의 결과를 뒷받침해야 할 것이다. 또한 음성장애 중증도에 따라 SOVTE의 효과가 차이가 나타날 수 있으나 본 연구에서는 중증도를 명확하게 구분하기 어려운 관계로 이에 대해서는 분석하지 못했으며, SOVTE의 종류나 진동원의 수 에 따른 차이도 살펴보지 못했다. 선행연구들에 의하면 빨대발성 에서 빨대의 직경이나 길이, 그리고 진동원의 수에 따라 성대에 미 치는 압력과 저항의 차이로 인한 생체 역학(biomechanism)의 차 이가 발생할 수 있다고 하였다(Kim et al., 2017; Titze, 2018). 이에 추후에는 음성장애의 중증도, 또는 SOVTE의 종류나 진동원의 수 에 따른 SOVTE 효과의 차이를 살펴보아야 할 것이다.

\section{REFERENCES}

Andrade, P. A., Wistbacka, G., Larsson, H., Södersten, M., Hammarberg, B., Simberg, S., ... \& Granqvist, S. (2016). The flow and pressure relationships in different tubes commonly used for semi-occluded vocal tract exercises. Journal of Voice, 30(1), 36-41.

Andrade, P. A., Wood, G., Ratcliffe, P., Epstein, R., Pijper, A., \& Svec, J. G. (2014). Electroglottographic study of seven semi-occluded exercises: LaxVox, straw, lip-trill, tongue-trill, humming, hand-over-mouth, and tonguetrill combined with hand-over-mouth. Journal of Voice, 28(5), 589-595.

Bele, I. V. (2005). Artificially lengthened and constricted vocal tract in vocal training methods. Logopedics Phoniatrics Vocology, 30(1), 34-40.

Borenstein, M., Hedges, L. V., Higgins, J. P., \& Rothstein, H. R. (2009). Introduction to meta-analysis. Hoboken, NJ: John Wiley \& Sons.

Cohen, S. M. (2010). Self-reported impact of dysphonia in a primary care population: an epidemiological study. The Laryngoscope, 120(10), 20222032.

Cordeiro, G. F., Montagnoli, A. N., Nemr, N. K., Menezes, M. H. M., \& Tsuji, D. H. (2012). Comparative analysis of the closed quotient for lip and tongue trills in relation to the sustained vowel /E/. Journal of Voice, 26(1), e17-e22. Costa, C. B., Costa, L. H. C., Oliveira, G., \& Behlau, M. (2011). Immediate ef- 
fects of the phonation into a straw exercise. Brazilian Journal of Otorhinolaryngology, 77(4), 461-465.

Croake, D. J., Andreatta, R. D., \& Stemple, J. C. (2017). Immediate effects of the vocal function exercises semi-occluded mouth posture on glottal airflow parameters: a preliminary study. Journal of Voice, 31(2), 245.e9-245. e14.

Dargin, T. C., DeLaunay, A., \& Searl, J. (2016). Semioccluded vocal tract exercises: changes in laryngeal and pharyngeal activity during stroboscopy. Journal of Voice, 30(3), 377.e1-377.e9.

de Andrade, B. M., Valença, E. H., Salvatori, R., Souza, A. H., Oliveira-Neto, L. A., Oliveira, A. H., ... \& Santos, M. P. (2018). Effects of therapy with semioccluded vocal tract and choir training on voice in adult individuals with congenital, isolated, untreated growth hormone deficiency. Journal of Voice. Advanced online publication. https://doi.org/10.1016/j.jvoice.2018.02.018

Denizoglu, I. I., Sahin, M., Bayrak, S., \& Uygun, M. N. (2018). Efficacy of Doctorvox voice therapy technique for mutational falsetto. Journal of Voice. Advanced online publication. https://doi.org/10.1016/j.jvoice.2018.05.012

Enflo, L., Sundberg, J., Romedahl, C., \& McAllister, A. (2013). Effects on vocal fold collision and phonation threshold pressure of resonance tube phonation with tube end in water. Journal of Speech, Language, and Hearing Research, 56(5), 1530-1538.

Frisancho, K., Salfate, L., Lizana, K., Guzman, M., Leiva, F., \& Quezada, C. (2018). Immediate effects of the semi-occluded ventilation mask on subjects diagnosed with functional dysphonia and subjects with normal voices. Journal of Voice. Advanced online publication. https://doi.org/10.1016/ j.jvoice.2018.10.004

Gaskill, C. S., \& Erickson, M. L. (2008). The effect of a voiced lip trill on estimated glottal closed quotient. Journal of Voice, 22(6), 634-643.

Gaskill, C. S., \& Quinney, D. M. (2012). The effect of resonance tubes on glottal contact quotient with and without task instruction: a comparison of trained and untrained voices. Journal of Voice, 26(3), e79-e93.

Gersten, R., Fuchs, L. S., Compton, D., Coyne, M., Greenwood, C., \& Innocenti, M. S. (2005). Quality indicators for group experimental and quasiexperimental research in special education. Exceptional Children, 71(2), 149-164.

Guzman, M., Acuña, G., Pacheco, F., Peralta, F., Romero, C., Vergara, C., \& Quezada, C. (2018). The impact of double source of vibration semioccluded voice exercises on objective and subjective outcomes in subjects with voice complaints. Journal of Voice, 32(6), 770.e1-770.e9.

Guzman, M., Calvache, C., Romero, L., Muñoz, D., Olavarria, C., Madrid, S.,
... \& Bortnem, C. (2015). Do different semi-occluded voice exercises affect vocal fold adduction differently in subjects diagnosed with hyperfunctional dysphonia? Folia Phoniatrica et Logopaedica, 67(2), 68-75.

Guzman, M., Castro, C., Madrid, S., Olavarria, C., Leiva, M., Muñoz, D., ... \& Laukkanen, A. M. (2016). Air pressure and contact quotient measures during different semioccluded postures in subjects with different voice conditions. Journal of Voice, 30(6), 759.e1-759.e10

Guzman, M., Jara, R., Olavarria, C., Caceres, P., Escuti, G., Medina, F., ... \& Laukkanen, A. M. (2017). Efficacy of water resistance therapy in subjects diagnosed with behavioral dysphonia: a randomized controlled trial. Journal of Voice, 31(3), 385.e1-385.e10

Guzman, M., Rubin, A., Muñoz, D., \& Jackson-Menaldi, C. (2013). Changes in glottal contact quotient during resonance tube phonation and phonation with vibrato. Journal of Voice, 27(3), 305-311.

Hamdan, A. L., Nassar, J., Al Zaghal, Z., El-Khoury, E., Bsat, M., \& Tabri, D. (2012). Glottal contact quotient in Mediterranean tongue trill. Journal of Voice, 26(5), 669.e11-669.e15.

Hampala, V., Laukkanen, A. M., Guzman, M. A., Horáček, J., \& Švec, J. G. (2015). Vocal fold adjustment caused by phonation into a tube: a doublecase study using computed tomography. Journal of Voice, 29(6), 733-742.

Higgins, J. P., \& Green, S. (2008). Cochrane handbook for systematic reviews of interventions. Oxford: Cochrane Collaboration.

Hwang, S. D. (2016). Meta-Analysis using OpenMeta, R, or RevMan. Daegu: Kyungpook National University Press.

Kapsner-Smith, M. R., Hunter, E. J., Kirkham, K., Cox, K., \& Titze, I. R. (2015). A randomized controlled trial of two semi-occluded vocal tract voice therapy protocols. Journal of Speech, Language, and Hearing Research, 58(3), 535-549.

Kim, J. S., Lee, D. W., Choi, C. H., \& Choi, S. H. (2017). Effects of laryngeal massage and semi-occluded vocal tract exercises for patients with hyperfunctional dysphonia. Communication Sciences \& Disorders, 22(4), 806-817.

Laukkanen, A. M., Titze, I. R., Hoffman, H., \& Finnegan, E. (2008). Effects of a semioccluded vocal tract on laryngeal muscle activity and glottal adduction in a single female subject. Folia Phoniatrica et Logopaedica, 60(6), 298311.

Lee, S. J., Lee, K. Y., Lim, J. Y., \& Choi, H. S. (2017). A comparison of acoustic \& electroglottographic measures according to voiced lip trill methods. Phonetics and Speech Sciences, 9(4), 107-114.

Lim, H. J., Choi, S. H., Kim, J. K., \& Choi, C. H. (2016). Effects of Lax Vox voice therapy in a patient with spasmodic dysphonia: a case report. Pho- 
netics and Speech Sciences, 8(2), 57-63.

Lipsey, M., \& Wilson, D. (2001). Practical meta-analysis. Thousand Oaks: Sage Publications.

Maia, M. E. O., Maia, M. O., Gama, A. C. C., \& Behlau, M. (2012). Immediate effects of the high-pitched blowing vocal exercise. Jornal da Sociedade Brasileira de Fonoaudiologia, 24(1), 1-6.

Mendes, A. L. F., do Carmo, R. D., de Araújo, A. M. G. D., Paranhos, L. R., da Mota, C. S. O., Schneiberg, S., ... \& Aragão, J. A. (2018). The effects of phonation into glass, plastic, and LaxVox tubes in singers: a systematic review. Journal of Voice, 33(3), 381.e1-381.e9.

Menezes, M. H., Ubrig-Zancanella, M. T., Cunha, M. G. B., Cordeiro, G. F., Nemr, K., \& Tsuji, D. H. (2011). The relationship between tongue trill performance duration and vocal changes in dysphonic women. Journal of Voice, 25(4), e167-e175.

Mills, R., Hays, C., Al-Ramahi, J., \& Jiang, J. J. (2017). Validation and evaluation of the effects of semi-occluded face mask straw phonation therapy methods on aerodynamic parameters in comparison to traditional methods. Journal of Voice, 31(3), 323-328.

Moreira, F. S., \& Gama, A. C. C. (2017). Effect of performance time of the high-pitched blowing vocal exercise in the voice of women. CoDAS, 29(1), e20160005.

Nam, I. C., Kim, S. Y., Joo, Y. H., Park, Y. H., Shim, M. R., Hwang, Y. S., \& Sun, D. I. (2018). Effects of voice therapy using the lip trill technique in patients with glottal gap. Journal of Voice. Advanced online publication. https://doi.org/10.1016/j.jvoice.2018.07.013

Paes, S. M., \& Behlau, M. (2017). Dosage dependent effect of high-resistance straw exercise in dysphonic and non-dysphonic women. CoDAS, 29(1), e20160048.

Paes, S. M., Zambon, F., Yamasaki, R., Simberg, S., \& Behlau, M. (2013). Immediate effects of the Finnish resonance tube method on behavioral dysphonia. Journal of Voice, 27(6), 717-722.

Portillo, M. P., Rojas, S., Guzman, M., \& Quezada, C. (2018). Comparison of effects produced by physiological versus traditional vocal warm-up in contemporary commercial music singers. Journal of Voice, 32(2), 200-208.

Ribeiro, V. V., de Oliveira, A. G., da Silva Vitor, J., Siqueira, L. T. D., Moreira, P. A. M., Brasolotto, A. G., \& Silverio, K. C. A. (2019). The effect of a voice therapy program based on the taxonomy of vocal therapy in women with behavioral dysphonia. Journal of Voice, 33(2), 256.e1-256.e16.

Robieux, C., Galant, C., Lagier, A., Legou, T., \& Giovanni, A. (2015). Direct measurement of pressures involved in vocal exercises using semi-occluded vocal tracts. Logopedics Phoniatrics Vocology, 40(3), 106-112.

Sielska-Badurek, E., Osuch-Wójcikiewicz, E., Sobol, M., Kazanecka, E., Rzepakowska, A., \& Niemczyk, K. (2017). Combined functional voice therapy in singers with muscle tension dysphonia in singing. Journal of Voice, 31(4), 509.e23-509.e31.

Simberg, S., \& Laine, A. (2007). The resonance tube method in voice therapy: description and practical implementations. Logopedics Phoniatrics Vocology, 32(4), 165-170.

Story, B. H., Laukkanen, A. M., \& Titze, I. R. (2000). Acoustic impedance of an artificially lengthened and constricted vocal tract. Journal of Voice, 14(4), 455-469.

Titze, I. R. (1988). The physics of small-amplitude oscillation of the vocal folds. The Journal of the Acoustical Society of America, 83(4), 1536-1552.

Titze, I. R. (2001). Acoustic interpretation of resonant voice. Journal of Voice, 15(4), 519-528.

Titze, I. R. (2006). Voice training and therapy with a semi-occluded vocal tract: rationale and scientific underpinnings. Journal of Speech, Language, and Hearing Research, 49(2), 448-459.

Titze, I. R. (2014). Bi-stable vocal fold adduction: a mechanism of modal-falsetto register shifts and mixed registration. The Journal of the Acoustical Society of America, 135(4), 2091-2101.

Titze, I. R. (2018). Major benefits of semi-occluded vocal tract exercises. Journal of Singing, 74(3), 311-312.

Titze, I. R., \& Laukkanen, A. M. (2007). Can vocal economy in phonation be increased with an artificially lengthened vocal tract? A computer modeling study. Logopedics Phoniatrics Vocology, 32(4), 147-156.

Titze, I. R., \& Story, B. H. (1997). Acoustic interactions of the voice source with the lower vocal tract. The Journal of the Acoustical Society of America, 101(4), 2234-2243.

Vlot, C., Ogawa, M., Hosokawa, K., Iwahashi, T., Kato, C., \& Inohara, H. (2017). Investigation of the immediate effects of humming on vocal fold vibration irregularity using electroglottography and high-speed laryngoscopy in patients with organic voice disorders. Journal of Voice, 31(1), 48-56.

Wan, X., Wang, W., Liu, J., \& Tong, T. (2014). Estimating the sample mean and standard deviation from the sample size, median, range and/or interquartile range. BMC Medical Research Methodology, 14(1), 135.

Yamasaki, R., Murano, E. Z., Gebrim, E., Hachiya, A., Montagnoli, A., Behlau, M., \& Tsuji, D. (2017). Vocal tract adjustments of dysphonic and non-dysphonic women pre-and post-flexible resonance tube in water exercise: a quantitative MRI study. Journal of Voice, 31(4), 442-454. 


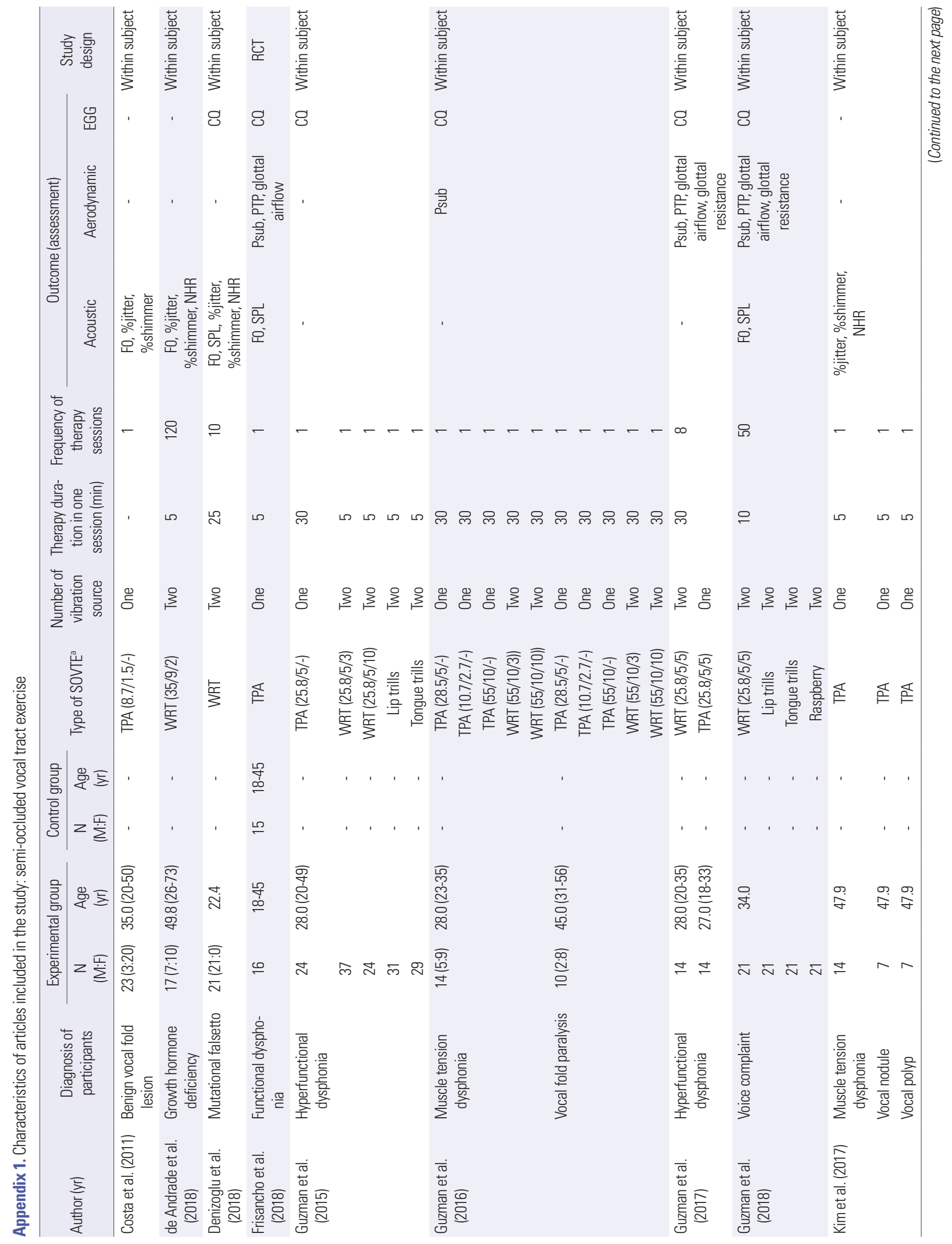




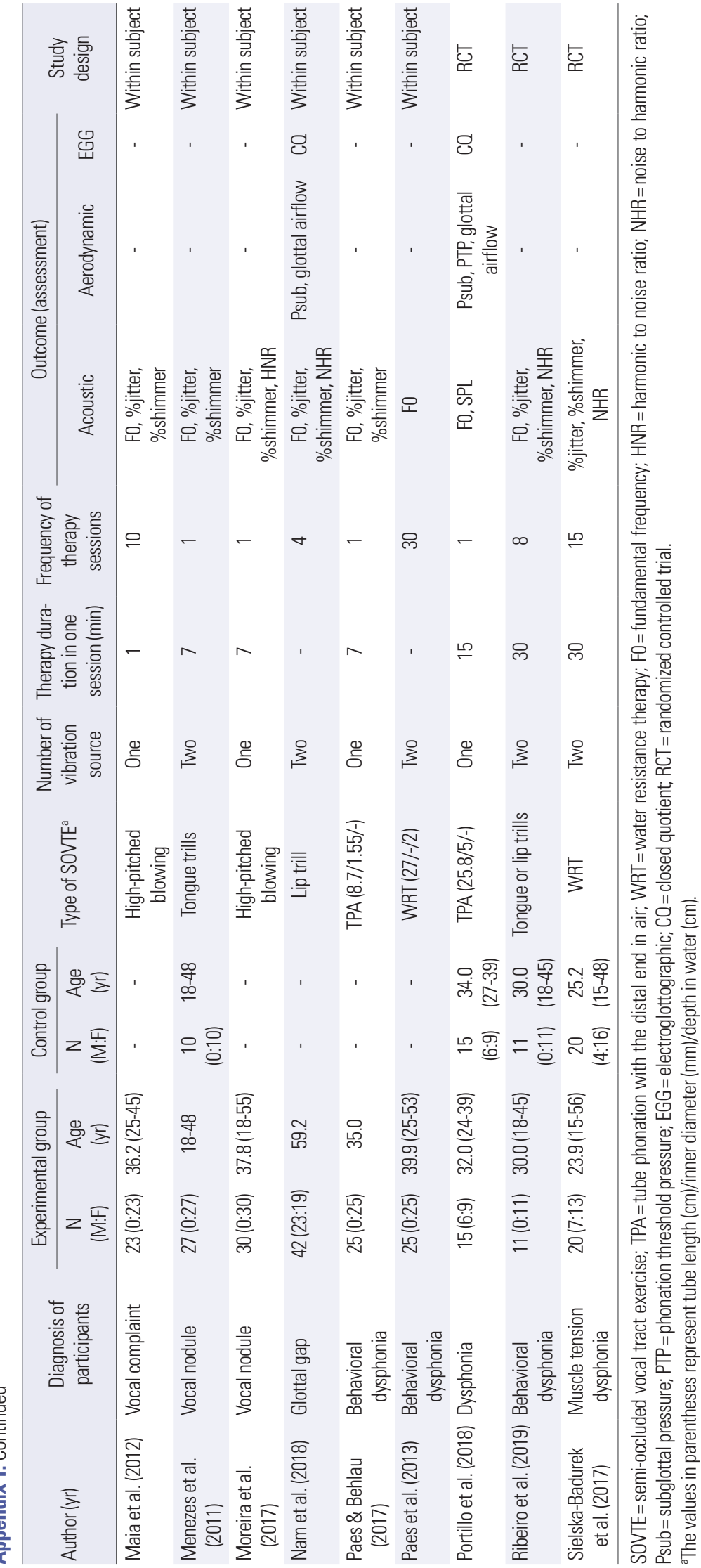




\section{국문초록}

\section{반폐쇄성도훈련의 중재효과에 대한 메타분석: 음향학적, 공기역학적, 전기성문파형 검사 김재옥}

강남대학교 교육대학원 언어치료교육전공

배경 및 목적: 본 연구는 음성장애 대상자에게 실시한 반폐쇄성도훈련(semi-occluded vocal tract exercise, SOVTE)의 음향학적, 공기 역학적 전기성문파형 검사에 미치는 효과를 메타분석을 통해 살펴보고자 하였다. 또한 음성장애 유형에 따라서도 이들의 차이가 있는 지를 분석하였다. 방법: 9 개의 데이터베이스 검색을 통해 2000년부터 2018년까지 학술지에 게재된 SOVTE의 음향학적, 공기역학적, 전 기성문파형 검사 효과에 관한 국내외 문헌들 중에서 포함 및 제외기준을 적용하여 18 편의 연구가 선정되었다. 18 편의 연구들은 SOVTE 하위 유형과 음성장애 유형에 따라 37개의 분석대상으로 구분되었다. Hedges' $g$ 를 사용하여 SOVTE의 음향학적(F0, SPL, $\%$ jitter, \%shimmer, NHR), 공기역학적(Psub, PTP, glottal airflow, glottal resistance) 및 전기성문파형(CQ) 검사의 효과크기를 산출하 였다. 결과: 음성장애 대상자에게 SOVTE를 실시한 효과를 메타분석으로 분석한 결과, 음향학적 검사는 유의하게 변화하였으나 공기 역학적 검사와 $\mathrm{CQ}$ 는 변화가 없었다. 그러나 각 검사의 하위 항목별로 살펴보면, \%jitter, \%shimmer, NHR, Psub, PTP, glottal resistance 는 유의하게 변화하였다. 음성장애 유형 간에도 음향학적 검사와\%jitter, 공기역학적 검사, Psub, 그리고 CQ가 유의한 차이를 보였다. 논 의 및 결론: 본 연구를 통해 SOVTE는 음향학적, 공기역학적 및 전기성문파형 검사에 의해 측정된 음성문제를 감소시키며, 과다기능적 음성장애나 성대폐쇄부전 음성장애에서 유용하게사용될 수 있음을 알수 있다.

핵심어: 메타분석, 반폐쇄성도훈련, 음향학적 검사, 공기역학적 검사, 전기성문파형 검사

본 연구는 2016학년도 강남대학교 교내연구비 지원에 의해 수행되었음.

\section{참고문헌}

김지성, 이동욱, 최철희, 최성희(2017). 후두마사지와 반폐쇄성도훈련이 과다기능적 음성장애 환자의 음성개선에 미치는 효과. Communication Sciences and Disorders, 22(4), 806-817.

이승진, 이광용, 임재열, 최홍식(2017). 입술 트릴의 방법에 따른 음향학적 및 전기성문파형검사 측정치 비교. 말소리와음성과학, 9(4), 107-114. 임혜진, 최성희, 김정규, 최철희(2016). 연축성 발성장애 환자의 Lax Vox 음성치료 효과. 말소리와음성과학, 8(2), 57-63.

황성동(2016). Free Software를 활용한 메타분석: Openmeta, R, RevMan을 중심으로. 대구: 경북대학교출판부.

\section{ORCID}

김재옥(https://orcid.org/0000-0002-6504-7294) 